\title{
VECTOR VALUED FOURIER ANALYSIS ON HYPERGROUPS
}

\author{
VishVESH KUMAR AND N. SHRAVAN KUMAR
}

Abstract. The aim of this paper is to prove the vector-valued version of the classical HausdorffYoung inequality for commutative hypergroups and compact hypergroups.

Mathematics subject classification (2010): 43A62, 43A30, 46L07.

Keywords and phrases: Commutative hypergroup, compact hypergroup, Fourier type, Schatten class operators, operator space, vector valued Fourier transform.

\section{REFERENCES}

[1] W. R. Bloom And Herbert Heyer, Harmonic analysis on probability measures on hypergroups, De Gruyter, Berlin (1995).

[2] S. DegEnfELD-SCHONBurg, Multipliers for hypergroups: Concrete Examples, Applications to Time series, Doctoral Dissertation, 2012.

[3] S. Degenfeld-SCHONBURG AND R. LASSER, Multipliers on $L^{p}$-spaces for hypergroups, Rocky Mountain J. Math., 43 (2013) 1115-1139.

[4] E. G. EFFros AND Z.-J. RuAN, Operator spaces, Oxford University Press, 2000.

[5] J. García-CUerva And J. PARCET, Vector-valued Hausdorff-Young inequality on compact groups, Proc. London Math. Soc., 88(3) (2004) 796-816.

[6] R. I. JEWETT, Space with an abstract convolution of measures, Adv. in math, 18 (1975) 1-101.

[7] V. KUMAR AND R. SARMA, The Hausdorff-Young inequality for Orlicz spaces on compact hypergroups, Colloquium Mathematicum (2019) (accepted).

[8] E. Michael, Topologies on spaces of subsets, Trans. Amer. Math. Soc., 71 (1951) 152-182.

[9] M. Milman, Complex interpolation and geometry of Banach spaces, Ann. Mat. Pura Appl., 136 (1984) 317-328.

[10] G. PISIER, Introduction to the Theory of Operator Spaces, London Mathematical Society Lecture Notes Series, Vol. 294, Cambridge University Press, 2003.

[11] G. PISIER, Non-commutative vector valued Lp-spaces and completely p-summing maps, Astérisque, 247 (1998) 1-111.

[12] R. C. VREM, Representations and harmonic analysis of compact hypergroups, Doctoral Dissertation, University of Oregon (1978)

[13] R. C. VREM, Harmonic analysis on compact hypergroups, Pacific J. Math., 85 (1979) 239-251. 